\title{
False type an in secretory otitis media (SOM): some
} case reports

\begin{abstract}
Secretory Otitis Media (SOM) appears as various types in tympanometry test including Type C1, Type C2, Type B, Type As. As we expect Type As in otosclerosis but we encounter Type An in many occasions, this is also the case in SOM. In this study, we will deal with case report of the patients with SOM, in which Type An is seen before and after treatment.

Keywords: secretory otitis media, tympanometry, type an, middle ear effusion
\end{abstract}

Volume 2 Issue 6 - 2015

\author{
Alireza Bina, Hamid Hosseini, Mina Nikpour \\ Atieh Hospital, Audiology Clinic, Iran
}

Correspondence: Alireza Bina,Atieh Hospital,Audiology Clinic, Iran, Tel 817-666-2926, Email alireza@yahoo.com

Received: January 27, 2015 | Published: June II, 2015

\section{Introduction}

Middle ear effusion may cause Type An tympanometry. Secretory otitis media appears as various types in tympanometry test including Type C1, Type C2, Type B, Type As and Type An, with the latter two being very close to each other. At the pressure of $0 \mathrm{daPa}$, Static Compliance (SC) lower than $0.3 \mathrm{cc}(0.1-0.29 \mathrm{cc})$ is called Type As, and between 0.3 and $1.6 \mathrm{cc}$ is called Type An. As we expect Type As in otosclerosis but we encounter Type An in many occasions, this is also the case in SOM and we see false Type An. ${ }^{1}$

In my clinical experience, it is seen more in SOM cases that are not completely treated or not caused hearing loss and air bone gap (mild $\mathrm{SOM}$ ). As in some cases of tympanic membrane perforation, hearing loss and air bone gap may not be developed, there are some cases of mild SOM, in which hearing loss and air bone gap is not caused. Acoustic reflex, especially IPSI reflex, should be absent due to Probe Effect in conductive hearing loss, but I had some patients with mild $\mathrm{SOM}$, in which hearing loss and air bone gap was not developed. ${ }^{2-3}$

Tympanometry test was Type An and IPSI reflex was present, which has been mentioned in Case Report 1. Due to SOM and labyrinthitis, this patient experienced vertigo. Since tympanometric and audiometric tests were normal, no center diagnosed SOM in the patient and referred the patient for MRI, while the patient's vertigo was due to SOM.

It is, therefore, of high importance to accurately diagnose SOM. In cases where unilateral SOM is developed, audiometric Weber test (Bone Weber) is very helpful. Even if SOM has not caused hearing loss and air bone gap, Weber test is lateralized towards the affected ear due to the occlusion effect in many cases.

Otoscopy and history taking are both helpful. Normal tympanic membrane should be completely white in color, and malleus should be normal in size. Presence of red vessels in tympanic membrane or pink or red tympanic membrane may be indicative of middle ear effusion, or the retracted malleus is a sign of SOM in otoscopy. In history taking, the patients state that they suffered from the problem recently or after a cold. The Eustachian Tube dysfunction and Middle ear Effusion are the reasons of ear Fullness and Autophonia. ${ }^{4-5}$

\section{Case report}

\section{Case report I}

An adult patient referred to our center, complaining of left ear tinnitus and vertigo. In history taking, the patient stated that she has suffered from the problem since one month ago. In otoscopy of left ear, redness was seen in some parts of tympanic membrane. In comparison, right tympanic membrane was completely white and normal in otoscopy.

Diapasonic Weber and Bone Weber tests were lateralized towards left ear at most frequencies. Audiometric and tympanometric tests were normal and even acoustic reflex (IPSI and Contra) was present in left ear, which was inconsistent with Probe Effect. After prescription of antibiotics for one period, nasal spray and nasal saline solution for improvement of Eustachian tube, left tympanic membrane became completely white in color, there was no redness in otoscopy, ${ }^{5-7}$ diapasonic Weber test returned to midline, tinnitus was discontinued, and vertigo was improved as said by the patient.

Normal results of tympanometric and audiometric tests before treatment in this patient were probably due to mild middle ear effusion, which did not cause dysfunction in mobility of the middle ear (Figure 1 \& 2).

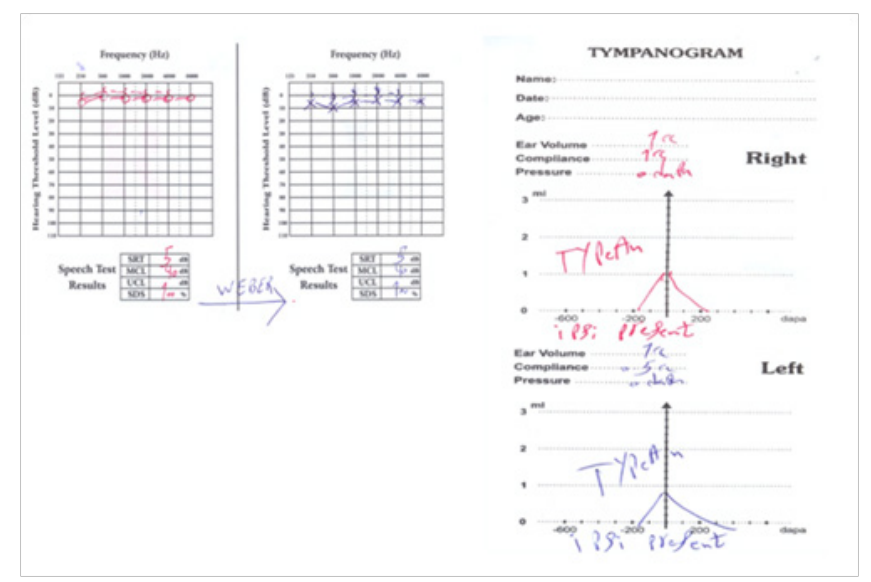

Figure I Audiogram and Tympanogram of Case No. I before Treatment.

\section{Case report 2 (Unilateral SOM)}

An adult patient referred to our clinic, complaining of hearing loss and left ear fullness. In otoscopy, right ear was normal, but left tympanic membrane and malleus were completely red. Tympanometry of right ear was Type An and acoustic reflex was present in right ear. In left ear, tympanometry was Type An with $\mathrm{SC}$ of $0.3 \mathrm{cc}$ and acoustic reflex was absent. ${ }^{8}$ 


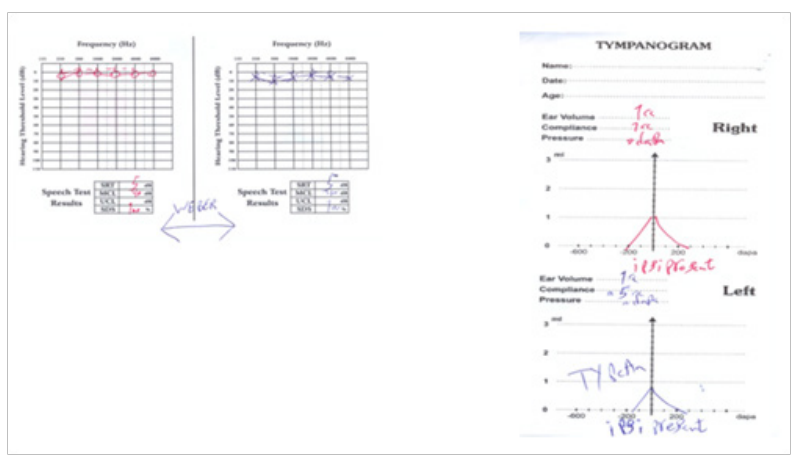

Figure 2 Audiogram and Tympanogram of Case No. I after Treatment.

In audiometry, right ear was normal, but there was conductive hearing loss and air bone gap in left ear at the frequency of $250 \mathrm{~Hz}$ Diapasonic Weber test was lateralized towards left ear due to occlusion effect. Rinne test in left ear was negative due to remarkable air bone gap. After two periods of antibiotic therapy, corticosteroid therapy, nasal spray and nasal saline solution for improvement of Eustachian tube, as prescribed by the physician, hearing loss and air bone gap of left ear were disappeared, Weber test returned to the midline, Rinne test of left ear became positive, static compliance of left ear increased from $0.3 \mathrm{cc}$ to $0.7 \mathrm{cc}$, and acoustic reflex became present (Figure $3 \&$ 4).

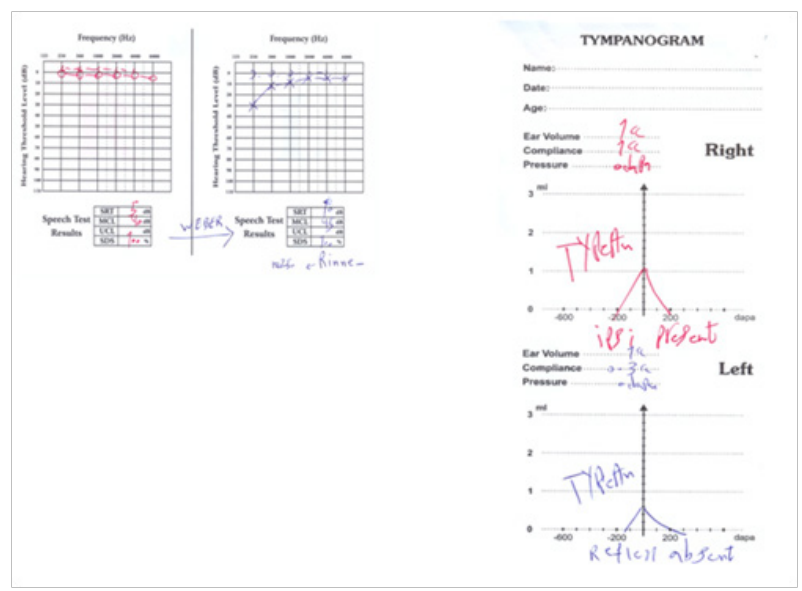

Figure 3 Audiogram and Tympanogram of Case No. 2 before Treatment.

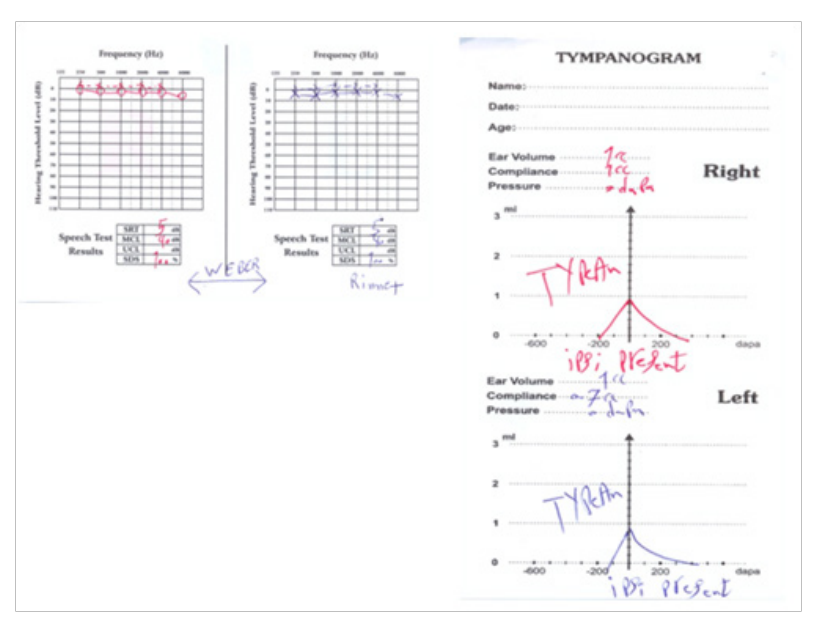

Figure 4 Audiogram and Tympanogram of Case No. 2 after Treatment.

\section{Case report 3}

The patient was a 6 years old child suffering from bilateral SOM due to adenoid hypertrophy. In both ears, tympanometry was Type $\mathrm{B}$ and acoustic reflex was D.N.T. In otoscopy of both ears, tympanic membrane and malleus were completely red. In audiometry, there was air bone gap at $30 \mathrm{~dB}$ and $40 \mathrm{~dB}$ in right and left ears, respectfully. ${ }^{9}$

After drug therapy for two periods, tympanic membrane was relatively improved, but there still was redness and inflammation. Tympanometry of both ears became Type An, with static compliance of $0.5 \mathrm{cc}$ and $0.4 \mathrm{cc}$ in right and left ears, respectfully. Acoustic reflex was absent in both ears and there was air bone gap at $10 \mathrm{~dB}$ and $15 \mathrm{~dB}$ in right and left ears, respectfully. ${ }^{10}$

By changing the antibiotic and prescribing other drugs, in next session, redness of tympanic membrane disappeared in both ears. In tympanometry, SC became $0.7 \mathrm{cc}$ and $0.6 \mathrm{cc}$ in right and left ears. Acoustic reflex was present in both ears and air bone gap was completely disappeared in both ears in audiometry (Figure 5-7).

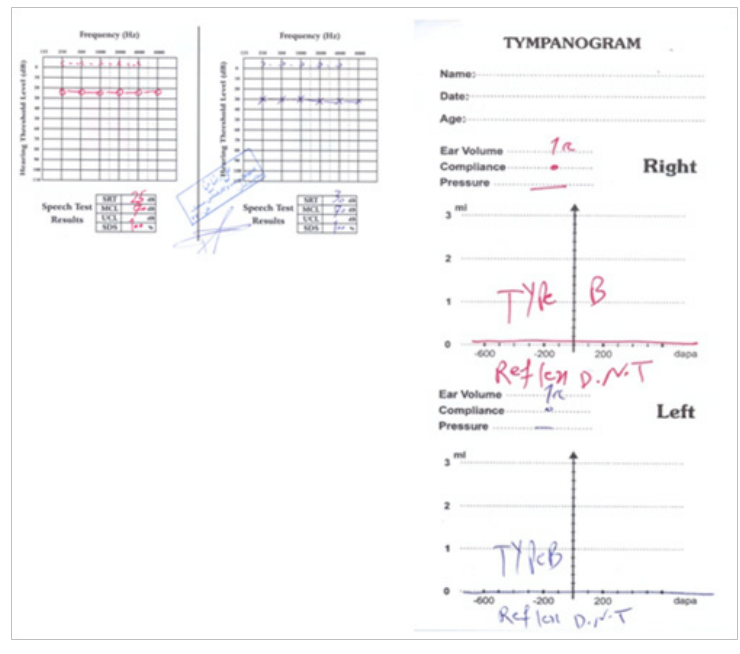

Figure 5 Audiogram and Tympanogram of Case No. 3 before Treatment.

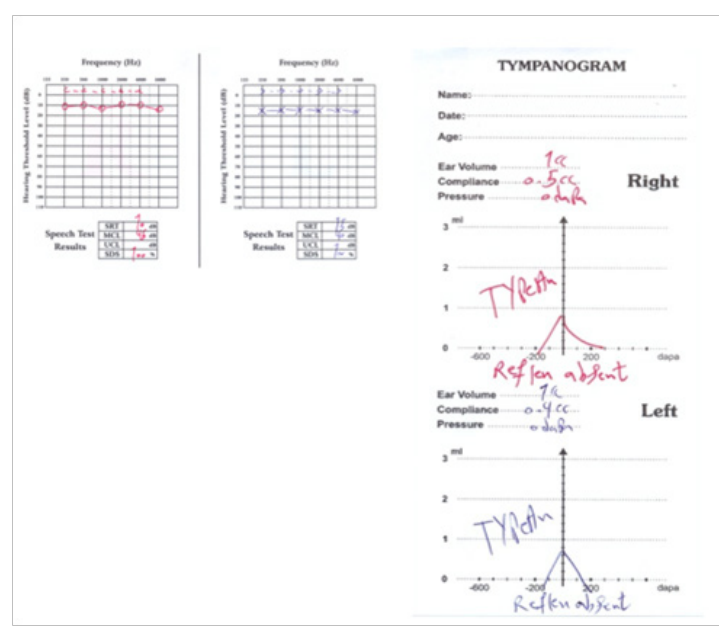

Figure 6 Audiogram and Tympanogram of Case No. 3 after Treatment for Two Periods.

\section{Case report 4}

An adult patient complaining of right ear fullness and tinnitus, having no compliant of left ear. In history taking, the patient stated 
that she experienced the problem after a cold. In otoscopy, left ear was normal, but right tympanic membrane and malleus were red. Tympanometry of left ear was normal (Type An), and acoustic reflex was present. ${ }^{11}$ In right ear, tympanometry was Type As with SC of $0.2 \mathrm{cc}$ and acoustic reflex was absent.

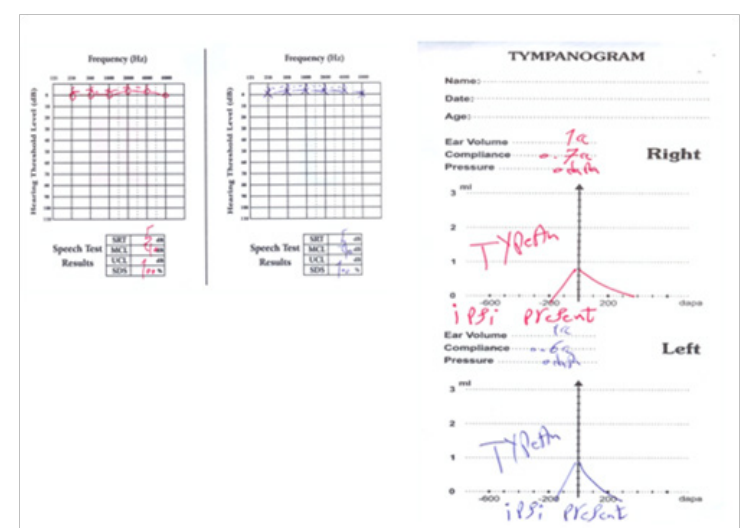

Figure 7 Audiogram and Tympanogram of Case No. 3 after Treatment for Three Periods.

In audiometry, left ear was normal, but there was a conductive hearing loss at high frequencies in right ear. I should concede that I was mistaking to diagnose this hearing loss at high frequency as acoustic trauma or sudden sensorineural hearing loss, but otoscopy of right ear indicated red tympanic membrane and diapasonic Weber test lateralized towards right ear both support conductive hearing loss in right ear.

After drug therapy for one period as prescribed by physician, tympanometry of right ear became Type An, SC became $0.4 \mathrm{cc}$, and acoustic reflex was still absent. In otoscopy, tympanic membrane was still red, but improved as compared to last session. In audiometry, hearing loss and air bone gap were decreased, but still remained.

Diapasonic Weber test still lateralized towards right ear. By changing antibiotics and prescribing corticosteroids by physician, in next session, right tympanic membrane was completely white in color, SC became $0.6 \mathrm{cc}$, acoustic reflex became present in right ear, Weber test returned to midline and air bone gap and hearing loss disappeared at high frequencies. ${ }^{12-13}$

In all cases, tympanometry test was performed by MADSEN and Interacoustics Tympanometers separately, and similar results were recorded (Figure 8-10).

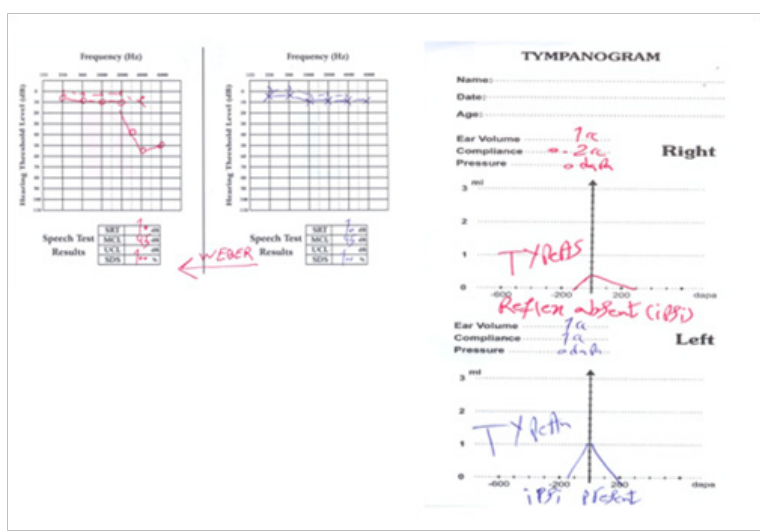

Figure 8 Audiogram and Tympanogram of Case No. 4 before Treatment.

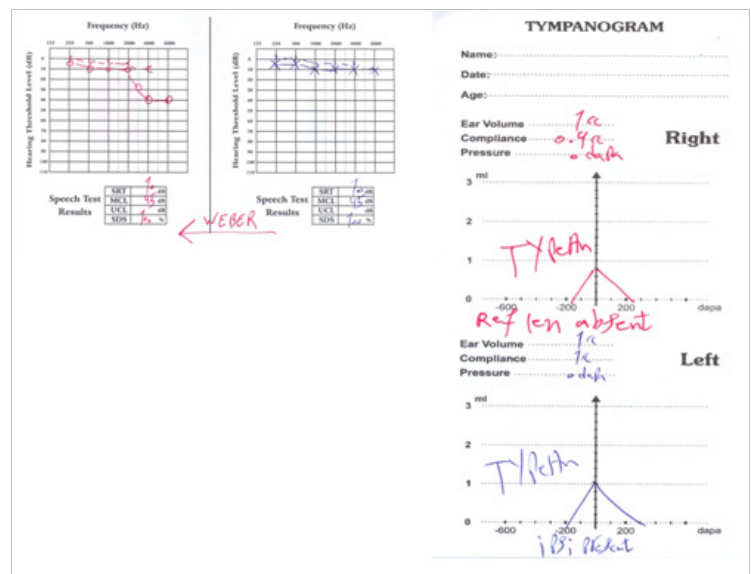

Figure 9 Audiogram and Tympanogram of Case No. 4 after Treatment for One Period.

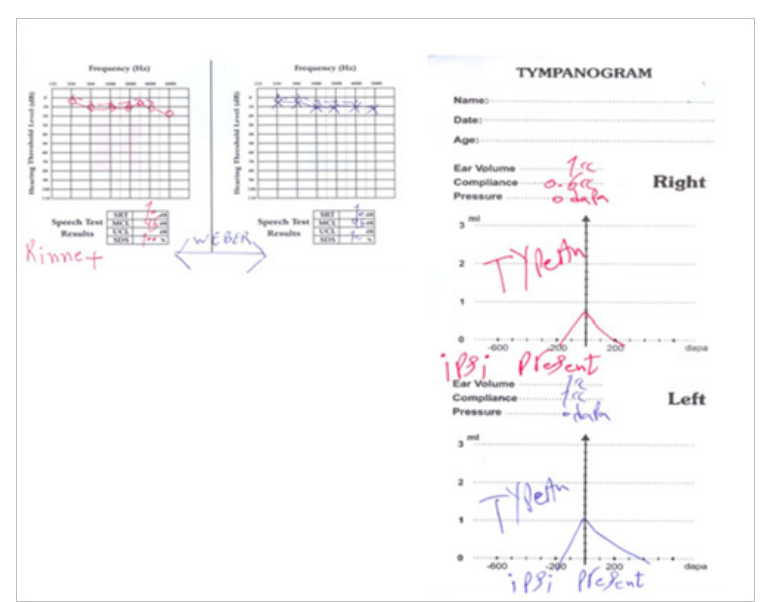

Figure 10 Audiogram and Tympanogram of Case No. 4 after Treatment for Two Periods.

\section{Conclusion}

One of the limitations of tympanometry test is identification of small lesions of the middle ear, but this does not trivialize this test. Performance of tympanometry test beside other tests including audiometry, diapasonic tests, otoscopy and accurate history taking is of the utmost importance. Increased SC after drug therapy in the reported cases was probably due to elimination of effusion-induced stiffness by drug therapy. Diagnosis of SOM is very important because in some patients, SOM leads to labyrinthitis, followed by hyperacusis, tinnitus, sudden hearing loss, or vertigo, which demands early diagnosis of SOM, so that the above-said symptoms may be prevented. Tympanometers which have been used in this study was Low and High Probe Tone Tympanometry (226, 1000 HZ). False Type An in SOM cases may not seen with new Wideband Tympanometer, up to $8000 \mathrm{HZ}$. More studies should be done to detect this issue.

\section{Acknowledgments}

None.

\section{Conflicts of interest}

Author declares there are no conflicts of interest. 


\section{Funding}

None.

\section{References}

1. Conover K . Earache. Emerg Med Clin North Am. 2013;31(2):413-442.

2. Mandel EM, Swarts JD, Casselbrant ML, et al. Eustachian Tube Function as a Predictor of the Recurrence of Middle ear effusion in Children. Laryngoscope. 2013;123(9):2285-2290.

3. Jacob Sadé. Secretory Otitis Media and its Sequelae, churchill living stone, New york, USA. 1979.

4. Rovers MM, Black N, Browning GG, et al. Grommets in Otitis Media with Effusion: An Individual Patient Data Meta-Analysis. Arch Dis Child. 2005;90(5):480-485.

5. Batler C, MacMillan H. Does Early Detection of Otitis Media with Effusion Prevent Delayed Language Development? Arch Dis Child. 2001;85(2):96-103.

6. Smirnova MG, Birchall JP, Pearson JP. The immunoregulatory and allergy-Associated cytokines in the aetiology of the otitis media with effusion. Mediators Inflamm.2004;13(2):75-88.
7. R Mills. The management of childhood otitis media with effusion. $J R$ Soc Med. 1996;89(3):132-134.

8. N Shah. Otitis Media and its Sequelae.JR Soc Med. 1991;84(10):581-586.

9. Ben H Senturia. Secretory Otitis Media. Proc R Soc Med. 56(88): $687-$ 695.

10. Bernstein JM, SchenKein HA, Genco RJ, et al. Complement activity in middle ear effusions. Clin Exp Immunol. 1963;33(2):340-346.

11. Ueyama T, Kurono Y, Shirabe K, et al. High incidence of Haemophilus influenzae in nasopharyngeal secretions and middle ear effusions as detected by PCR. J Clin Microbiol . 1995;33(7):1835-1838.

12. Ross J Roeser, Michael valente, Holly Hosford-Dunn. Audiology: Diagnosis. ( $2^{\text {nd }}$ edn), Thieme publishers, Germany. 2008.

13. Jack katz. Clinical audiology. In: Larry Medwetsky, editors. et al. Handbook of clinical audiology. $6^{\text {th }}$ ed. Wolters kluwer, Lippincott ,Williams \& Wilkins.USA. 2009. 